\section{A ARTE DE ESCREVER CARTAS}

Anônimo de Bolonha, Erasmo de Rotterdam e Justo Lípsio.

Organização, tradução e notas de Emerson Tin

[Sāo Paulo: Editora da Unicamp, 2005, 165 p.]

A correspondência por meio de cartas pode ser considerada a arte do diálogo que substitui a comunicação oral e a presença física das pessoas envolvidas. A epístola já foi objeto de discussões e tratados no que diz respeito a seus modelos de estilo e seus objetivos. No livro $A$ arte de escrever cartas - Anônimo de Bolonha, Erasmo de Rotterdam e Justo Lípsio, as cartas aparecem como tema de tratados que discutem e ensinam a arte epistolográfica.

O organizador desta importante coletânea mostra que a epistolografia tem regras para seus vários modelos, elaborados ao longo da História. Na introdução da obra, Emerson Tin apresenta ao leitor as principais referências epistolares do Ocidente, iniciando pela Antiguidade até chegar aos autores reunidos no título. Observa que na Antiguidade as principais referências à arte epistolar ou estão dispersas na correspondência do período ou integram tratados de retórica.

Inicia por Demétrio, que, em seu tratado De elocutione, escrito provavelmente entre os séculos I. a C. e I. d.C., constituiu a "primeira obra a expor regras teóricas sobre epistolografia" (p. 19). Esse tratado estabelece que as cartas devem ser concebidas como parte de um diálogo, mas de maneira mais elaborada, por serem escritas e enviadas a alguém. A feitura da missiva deve, no entanto, adotar um estilo simples, que mais se aproxime da conversa entre amigos. Para Demétrio, constituiriam um erro cartas muito extensas ou pomposas: estas, ao invés de epistolografia, seriam tratados em forma epistolar, como os de Platão e de Tucídides. Como o período helenístico é marcado pela crescente diferenciação entre a epístola pública e a privada, Demétrio também versou sobre o tema. $\mathrm{O}$ autor ensina sobre a liberdade das cartas: devem ser amistosas, com expressões cordiais e provérbios, se destinadas a pessoas próximas; para o Estado ou a pessoas régias, devem adotar um tom ligeiramente elevado. Os pensadores que sucederam Demétrio operaram variações sobre o tema.

Marco Túlio Cícero (106-43 a.C.), segundo Tin, não escreveu tratados, porém elaborou diversos conceitos a respeito da arte epistolográfica, com base na teoria epistolar grega. No Renascimento, suas cartas foram consideradas modelo absoluto para a escrita de missivas. Cícero considera a carta uma conversação por intermédio da escrita, um meio de manifestação do caráter de quem escreve. A estrutura da carta ciceroniana orienta o gênero epistolar não só para informar, mas também para persuadir. Seus elementos fundamentais baseiam-se na abertura, no setor central e na conclusão.

Sêneca (4 a.C.-65 d.C.), como Cícero, não teorizou sobre a escrita de epístolas, mas elaborou certos conceitos sobre a arte de escrevê-las em Epistulae morales ad Lucilium. A expressão epistolar, para Sêneca, contém o poder de tornar presente o destinatário. $\mathrm{O}$ estilo deve adotar um tom coloquial, como uma conversa entre amigos, sem que isso signifique ausência de regras para o gênero.

Já Filóstrato de Lemnos (nascido por volta de 190 d.C.), autor do pequeno tratado De epistulis, do século III d.C., reflete sobre o estilo epistolar "apropriado", 
que, segundo ele, deve "na aparência ser mais ático do que o discurso diário, mas mais ordinário do que seja o aticismo" (p. 26). A clareza é o guia de todo discurso e, para a epistolografia, também o melhor modo de persuasão, aconselha Filóstrato.

Emerson Tin também apresenta as principais propostas de Gregório de Nazianzeno (c. 329-c. 390) para a arte de escrever cartas. Gregório pondera sobre a extensão da carta, indicando que a epístola deve ter três qualidades - concisão, clareza e graça -, sempre pautadas pelo objetivo a que se destinam, pela beleza da persuasão e pelo entendimento imediato. E, para que não sejam de mau gosto, cumpre ao escrevê-las evitarem-se a aridez do discurso ou o uso indevido de ditos sentenciosos, provérbios, gracejos ou enigmas.

$\mathrm{O}$ último autor da Antiguidade destacado por Tin é Caio Júlio Victor, que, em sua Ars rhetorica, dedica capítulo às cartas, na esteira de Cícero e Quintiliano. Ali afirma que muitas das diretrizes do discurso oral podem ser aplicadas às missivas, divididas por ele como de negócios ou familiares. A primeira teria matéria oficial e séria, com admissão de fatos históricos narrados e de discurso mais erudito, quando os mesmos não corrompem o estilo peculiar das cartas. A familiar deveria ser breve e clara, de modo a evitar questionamentos sobre expressões sibilinas, já que nas cartas não é possível interrogar o remetente para esclarecê-los.

Entretanto, na Idade Média, por consequência dos negócios públicos civis ou eclesiásticos, as epístolas exigiram um estilo formalmente mais rígido. Nascia a Ars dictaminis, cujos tratados são modelados pelo discurso clássico e pela adaptação da tradicional divisão do discurso às peculiaridades da carta.
No início do século XI, Bolonha passa a ser o centro da Ars dictaminis, onde um dos primeiros nomes a se destacar é o de Adalberto Samaritano. No final do século XI, essas "regras de composição das cartas" encontraram centro difusor no convento beneditino de Montecassino, em torno de Alberico de Montecassino e Juan de Gaeta. Hugo de Bolonha, professor de retórica na escola da catedral de Bolonha, aumentou os tratados sobre a dictaminis, ligando o texto de Cícero e Salústio ao de São Paulo. Para Hugo, há dois tipos de dictaminis: o prosaico e o métrico, segundo a composição em prosa ou em versos. E a carta se divide em três partes: exórdio (que predispõe o leitor para o que se segue); narração (o relato) e conclusão.

Com a escola francesa, no início do século XIII, o dictamen era ensinado, principalmente, em conjunto com a gramática, enquanto em Bolonha era associado com o estudo de Direito. Os trabalhos dos professores e as práticas dos notários franceses, que trabalhavam na chancelaria papal, cresceram em popularidade até influenciarem fortemente o ensino do dictamen em Bolonha. Nos tratados dessa safra, há, segundo as palavras de Emerson Tin, uma "grande preocupação com a demonstração de cortesia e etiqueta nas cartas, praticada numa sociedade altamente hierarquizada [...]. Características como brevidade e clareza, já prescritas pela tratadística antiga, são reafirmadas, o que as faz parecer cada vez mais elementos próprios do gênero epistolar" (p. 37).

A partir de então, a maioria dos tratados epistolares tornaram-se, porém, unânimes em "criticar e até mesmo ridicularizar a rigidez e o formalismo" (p. 43) apresentados pela ars dictaminis medieval. Tal tendência 
vantagem conforme a idade do remetente. Vale ressaltar que Emerson Tin, em seu prefácio, ainda fornece valiosa súmula de outra obra de Erasmo, Opus de conscribendis epistolis (1502), onde se encontra uma conhecida definição da carta: rex tam multiplex propeque ad infinitum varia, ou seja, "uma coisa tão diversificada [múltipla], que pode variar infinitamente"

Chegamos, assim, ao último tratado, "A arte de escrever cartas", do humanista flamengo Justo Lípsio. Composto por treze capítulos, inicia-se com uma breve revisão etimológica da palavra epístola e um levantamento de aspectos históricos do objeto carta. A seguir define a missiva: "é uma notícia escrita de um espírito a outro ausente, ou quase ausente". O "quase ausente" se refere à troca de correspondência entre pessoas da mesma cidade, bairro e, às vezes, da mesma moradia. Lípsio divide, então, a epístola em duas partes: matéria e estilo.

O primeiro item, tema do capítulo três, define o conteúdo da carta subdividindo-o em dois princípios: o convencional e o variável. O primeiro refere-se à matéria repetida em toda carta, elemento quase obrigatório, caso das preliminares, parte da abertura da missiva que contém a saudação. Outro item "convencional" é a conclusão, cerne do capítulo quatro. Lípsio afirma que a conclusão é composta por cinco partes, também convencionais: valedictio (a saudação propriamente dita, "Adeus", "Olá"); indicação de lugar; indicação de tempo; fecho complementar e assinatura. Interessante notar a atenção do tratadista ao lacre e ao barbante como elementos de garantia do sigilo e da credibilidade.

O quinto capítulo é então dedicado ao outro princípio do conteúdo da carta, o variável. Trata-se do teor mutável da epístola. Tal matéria "é múltipla: não menos extensa que a própria vida" (p. 139). Diante dessa grandeza o autor propõe a divisão em três tipos de cartas: 1) Séria - pode ser pública (narrações; dissertações; deliberações das coisas de estado, de guerra, de paz; entre outras) ou privada (consolações; recordações; petições; repreensões; desculpas; conselhos e elogios); 2) Douta, ligada ao conhecimento ou à sabedoria - pode ser literária, filosófica ou teológica; 3) Familiar, "que troca às coisas nossas ou em torno de nós, às coisas frequentes na vida. [...] Com as duas formas anteriores, [...] frequentemente a Familiar está mesclada (p. 139-40).

Para discutir o estilo, o tratadista inicia pela invenção e organização, aconselhando a desordem própria da fala: "como nas conversas de algo descuidado e desorganizado gostamos, assim aqui" (p. 140). A partir de tal proposta, vem o capítulo seis, voltado ao estilo coloquial da epístola, subdividido em geralmente e em particularmente. O primeiro - geralmente - diz respeito à estrutura da missiva: prevê brevidade, clareza, simplicidade, elegância e decoro. O segundo - particularmente - refere-se à sintaxe da carta: a melhor dicção o remetente adquire imitando, ensina Lípsio. Entretanto, adverte que é preciso saber "quem e quando tu deves ler; o que e de quem tu deves selecionar; o que tu deves imitar e o que evitar" (p. 148). O que ler vincula-se à idade ou ao nível intelectual do correspondente. Neste ponto o autor faz uma diferença entre níveis de maturidade para a imitação: a pueril, a crescente e a adulta. Para cada fase um grupo de escritores clássicos é indicado. Já no penúltimo capítulo, o tratadista debate o que aproveitar dessa leitura. Ele então 
aprimora o conceito de imitação e indica a citação, ou melhor, excertos. Aconselha ao missivista a coleção de bons trechos de textos e que os carregue, tal qual tesouros, em "livrinhos" No último item, Lípsio orienta sobre "o que imitar e o que evitar" com recomendações específicas para cada fase de maturidade. Mas, de modo geral, indica uma progressiva independência da imitação na busca de estilo próprio.

A arte de escrever cartas, além de tornar textos clássicos acessíveis, em boa edição de língua portuguesa, contribui para destacar o aspecto retórico do gênero epistolar, assunto muitas vezes enevoado por uma visão herdada do Romantismo, que liga os estudos sobre correspondências ao confessional. O ensaio introdutório e as traduções de Emerson Tin concorrem efetivamente para o enriquecimento da fortuna crítica brasileira sobre a epistolografia.

Aline Ulrich é mestre em Literatura Brasileira pela Universidade de São Paulo, bolsista do CNPq.

Elizabeth da P. Cardoso é doutoranda em Teoria Literária e Literatura Comparada na Universidade de São Paulo, bolsista da FAPESP.

\section{LA ESCRITURA EPISTOLAR.}

Nora Esperanza Bouvet. [Buenos Aires: Editorial Universitaria de Buenos Aires (EUDEBA), 2006, 220 p.]

Nas últimas décadas, no âmbito das ciências humanas na América Latina, proliferaram ediçōes de cartas, ocupando lugar de destaque - o que parece justificar o trabalho de compilação - aquelas que recuperam vínculos pessoais entre personalidades do campo político ou sociocultural. Reunidas em coletâneas, antologias, edições comentadas e/ou anotadas, ou inseridas, como anexos ou apêndices ad hoc, em ediçōes críticas ou genéticas de obras literárias, ou ainda, constituindo volumes em coleções de fontes primárias, as cartas foram situadas em um novo patamar: tornaram-se objeto de estudo.

Com esse novo status, a carta foi abordada, revisitada, principalmente a partir de interesses específicos de diferentes áreas. A história, por exemplo, continua colocando à prova suas fontes documentais, marcadas pelo valor relativo, oblíquas, mas certamente irrefutáveis. Os estudos literários, por sua vez, tanto os de crítica literária, quanto os de especulação teórica, vêm promovendo leituras que focalizam as estratégias discursivas de um gênero situado entre a oralidade e a escrita, entre o prosaico e a literatura, entre o público e privado. Por que legitimar o estudo das cartas? Quais são suas potencialidades de significação e sua utilidade no campo de estudo das ciências humanas e sociais? Como dimensioná-las e construí-las como objeto de estudo, passíveis de uma sistematização, se observamos a carência de uma metodologia? Estas são apenas algumas das principais questões propostas nas 